\title{
Acquisition of Hordeum vulgare (Beverage) prospective against adiposity among female trial
}

Nizwa Itrat ${ }^{1,2^{*}}$, Anum Nazir ${ }^{1,2}$, Minal Ali $^{1}$, Uswa Ahmad $^{3}$ and Zain Mushtaq ${ }^{4,5}$

1. Department of Nutrition and Dietetics, the University of Faisalabad, Punjab Pakistan

2. Department of Nutritional Science, Government College University Faisalabad Punjab Pakistan

3. School Human Nutrition and Dietetics, Minhaj University Lahore, Pakistan

4. Department of Soil Science, Punjab University Lahore, Punjab, Pakistan

5. Institute of Soil and Environment Sciences, University of Agriculture, Faisalabad, Pakistan

*Corresponding author's email: Nizwa.Qamar@tuf.edu.pk

Citation

Nizwa Itrat, Anum Nazir, Minal Ali, Uswa Ahmad and Zain Mushtaq. Acquisition of Hordeum vulgare (Beverage) prospective against adiposity among female trial. Pure and Applied Biology. Vol. 11, Issue 3, pp755-761. http://dx.doi.org/10.19045/bspab.2022.110076

\begin{tabular}{llll}
\hline \hline Received: 21/08/2021 & Revised: 28/10/2021 & Accepted: 12/11/2021 & Online First: 18/11/2021 \\
\hline \hline
\end{tabular}

\section{Abstract}

Obesity is the most prevalent disease in today's world. The etiology of obesity depends on various factors like genetics, metabolic factors, lifestyle. Obesity leads to several chronic diseases and is fatal thus need to be managed and treated. Barley helps in prevention of several chronic diseases like obesity, diabetes, high blood pressure, hyperlipidaemia, colon cancer, gall stones with aid of bioactive components present in it. Barley grain (Hordeum Vulgare) is one of the ancient crops produced in today's world and is ranked fourth among cereals because of its highest cultivation worldwide. Comparatively barley grain is easier to cultivate as it can endure environmental stress and is inexpensive. Barley has greatest functional value among cereal group on account of its low glycaemic index, high concentration of Beta-glucan and resistant starch. Beta-glucan is gaining immense consideration worldwide because of its health benefits. The present study was conducted in order to determine the effectiveness of barley grain on weight loss in obese patients. Human subjects were taken on the basis of their medical history, anthropometric measurements, clinical assessment, lifestyle and dietary habits. The obese patients were provided with $120 \mathrm{ml}$ of barley water daily for about 12 weeks. Their weight and anthropometric measurements were taken before, during and after the trial. The results were analysed and the data obtained was subjected to statistical analysis. The results of the research showed that the effect of barley water on weight loss is significant. It was able to significantly improve anthropometric values. The effect was most significant on weight, BMI and waist circumference. Therefore, the study concluded that barley water was effective in reducing weight in obese females.

Keywords: Obesity; Barley grain; Beta-glucan; Weight loss; Barley water; Anthropometric measurements

\section{Introduction}

Various health risks are associated with obesity. If left untreated can further increase complications like cardiovascular diseases, renal diseases [1]. Obesity can be observed in both children and adults. In adults, if the body 
mass index is equal or greater than 30 and in adolescents/children if BMI is at 95th percentile or greater, will come under the category of overweight/obesity [2]. In last 25 years obesity is affecting more and more people, almost 2 billion individuals worldwide. Obesity can be considered as a pandemic [3].

Obesity is linked to many chronic illnesses including CVDs, stroke, cancer, diabetes, liver disorders, polyps etc. Adams et al study indicated that obesity raise mortality rates by 20 to $40 \%$ in overweight individuals than in healthy people [4].

Barley is one of the ancient crops among cereal group produced in today's world. Barley ranks fourth among cereals (wheat, rice, maize) as it is highest cultivated and grown crop globally. When compared to other cereals barley can easily bear the environment stress because of its structure and early maturing thus is more economical and convenient to cultivate [5].

If whole barley flour is consumed daily and regularly it can help in preventing chronic diseases specially obesity, diabetes, hyperlipidaemia, colon cancer, gallstones and high blood pressure [6]. This is achieved by the bioactive components present in barley specially Beta-glucan, fiber, vitamins and minerals [5]. Barely grains are low glycemic index food having high concentration of beta-glucan plus resistant starch therefore have greatest functional value in cereals group as it is also rich in functional components [6]. Because of the health benefits of Beta-glucan, barley is gaining extraordinary attention from all around the world including nutritionists, scientists, consumers and food manufacturers [7]. Thus, the aim of the study was to conduct proximate analysis of barley powder, formulate barley water using a specified concentration of barley and to determine the effectiveness of barley on weight loss in obese patients.

\section{Materials and Methods}

Barley grain, scientifically known as Hordeum Vulgare was procured from Imtiaz Supermarket Faisalabad.

\section{Characterisation of barley}

Barley was grinder into fine powder for the purpose of proximate analysis (crude fibre, moisture content, ash content, crude fat, crude protein, nitrogen free extract) [8].

\section{Formulation of barley water}

$10 \mathrm{~g}$ of barley grains was measured with the help of a kitchen scale. The barley grains were washed and drained properly with clean water. After washing barley grains was soaked overnight in 3/4 cup of water. Later in the morning, the barley grains were drained and were added to a saucepan. Then 2 cups of water were added in the same saucepan along with the soaked barley grains on high flame. When the first boil appeared, the flame was changed to low and the saucepan was kept on stove with covered lid for about 30 mins or until the barley grains became soft. The water was cooked enough that the water was reduced to $1 / 2$ cup. Lastly the barley water was strained with the help of a sieve and barley water was ready [9].

\section{Efficacy study}

The bio evaluation was carried out to investigate the effect of barley grain in obese patients. Human subjects were included from Faisalabad on the basis of their evaluation of anthropometric measurements, clinical assessment, medical history, dietary history and lifestyle with their consent without any kind of pressure for being the part of the study. The human efficacy was conducted in three groups, 10 members each. Two treatment groups were chosen $\mathrm{G}_{1}$ and $\mathrm{G}_{2}$. $\mathrm{G}_{1}$ received $120 \mathrm{ml}$ of barley water made with $10 \mathrm{~g}$ of barley. $\mathrm{G}_{2}$ received $120 \mathrm{ml}$ of barley water made with $5 \mathrm{~g}$ of barley daily for 12 weeks. Their weight along with other anthropometric measurements were observed before, during and after the trial. 
The females were of age group 21-45 years and had no chronic disease. They were neither pregnant nor lactating. The study was conducted for 12 weeks. The control group was not given any thing while the treatment groups were given $10 \mathrm{~g}$ and $5 \mathrm{~g}$ barley per day. The anthropometric measurements (weight, body mass index, waist circumference, waist to hip ratio) were taken at zero day and after every week for 12 weeks.

\section{Statistical analysis}

Results obtained from different studies were subjected to SPSS version 9.0 and statistically analysis using Analysis of
Variance Technique (ANOVA) under Completely Randomized Design (CRD) to determine the level of significance.

\section{Results and Discussion}

According to the results of proximate analysis of barley powder, the barley grain powder contains $8.09 \%$ of the moisture content. Total ash content present in barley powder sample is weighted to be $3.95 \%$. Percentage of crude fiber present in barley powder sample is $11.37 \%$ whereas, crude fat, crude protein and nitrogen free extracts calculated are $2.42 \%, 12.46 \%$ and 61.71 respectively (Fig. 1).

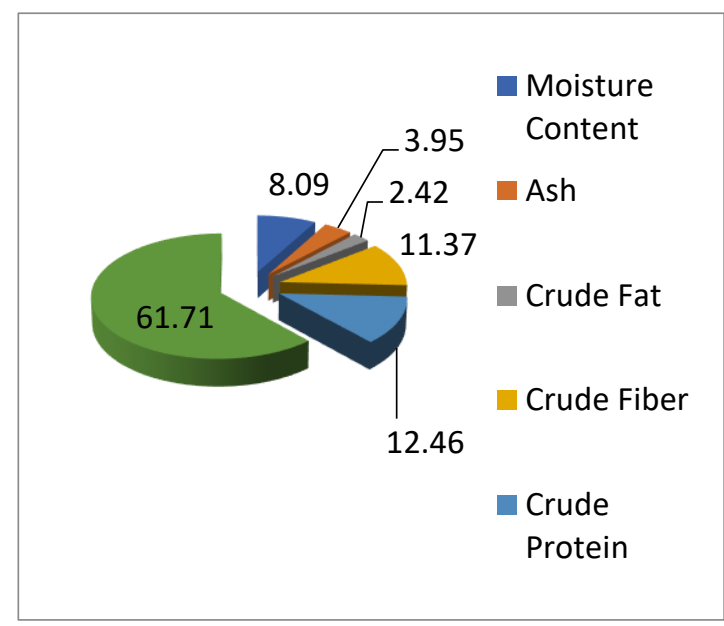

Figure 1. Nutritional Composition of barley grain powder (\%)

A research in 2019 was conducted to determine the proximate analysis of five different varieties of malting barley that belongs to the Mexican origin. The statistical results of the proximate analysis showed the composition of different varieties of barley which on average have increased quantity of total carbohydrates $(76.84 \%)$, moisture $(10.34 \%)$, fiber $(5.65 \%)$, ash $(2.36 \%)$, protein $(12.47 \%)$ and total fat $(2.67 \%)$. Along with this composition malting barley varieties also provide with enough energy and nutrients [10].

\section{Efficacy}

The values of the weight of $\mathrm{G}_{1}$ at the initial point before the trial started was $69.1 \pm 9.2$ which dropped to $69.45 \pm 8.1$ in first 4 weeks. This value further dropped to $68.43 \pm 7.9$ at day 60. And a greater decline was observed in the last 4 weeks with values $67.01 \pm 8.01$ when compared to the readings at day 0 as also depicted by figure 2 . The values of the weight of $\mathrm{G}_{2}$ at the initial point before the trial started was $70.17 \pm 6.2$ which dropped to $70.15 \pm 5.1$ in first 4 weeks. This value further dropped to $69.99 \pm 7.1$ at day 60 . And a greater decline was observed in the last 4 weeks with values $69.75 \pm 4.1$ when compared to the readings at day 0 as also depicted by (Fig. 2). The results of $G_{1}$ were highly significant as compared to $\mathrm{G}_{2}$. The results of $\mathrm{G}_{2}$ were not significant enough but when compared to the 
control group the results were significant. The study by Rahmani et al. [11] also shows a significant reduction in body weight in obese patients due to the presence of beta glucan in barley.

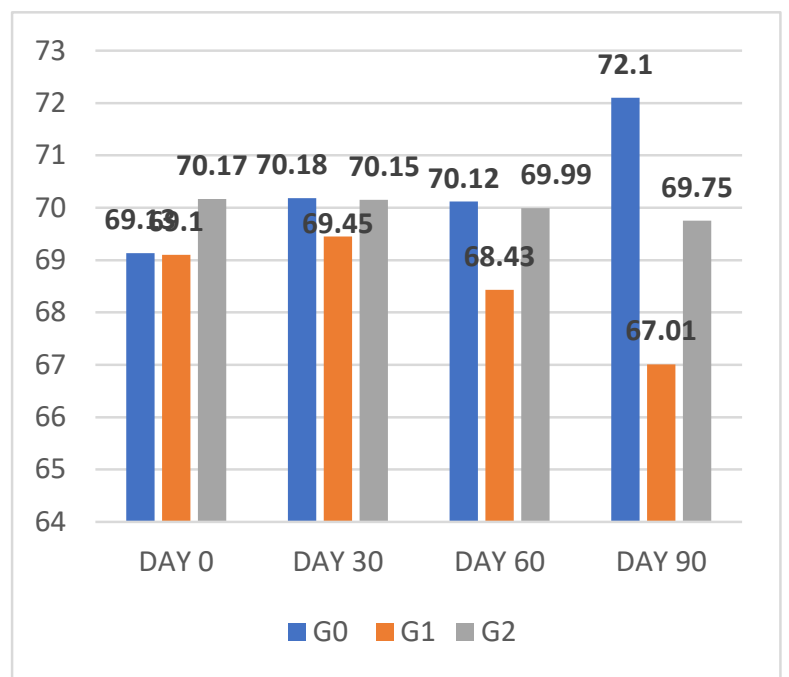

Figure 2. Means for weight of females attesting the effect of barley water

The values of the body mass index of $\mathrm{G}_{1}$ at day 0 before the trial started was $27.67 \pm 3.32$ which decreased to $27.3 \pm 3.34$ at day 30 . This value of body mass index further decreased to $26.98 \pm 3.3$ at day 60 . And it further decreased to $26.35 \pm 3.30$ at day 90 . And the values of the body mass index of $\mathrm{G}_{2}$ at day 0 before the trial started was $28.75 \pm 3.23$ which slightly decreased to $28.73 \pm 3.33$ at day 30 .
This value of body mass index was almost same $28.72 \pm 3.2$ at day 60 . And it further decreased to $28.69 \pm 3.1$ at day 90 . The results of $\mathrm{G}_{2}$ were less significant as compared to $\mathrm{G}_{1}$ but significant enough when compared to $\mathrm{G}_{\mathrm{o}}$. Whereas, the values of the control group increased from $26.41 \pm 2.27$ at day 0 to $27.55 \pm 2.29$ at day 90 (Fig. 3).

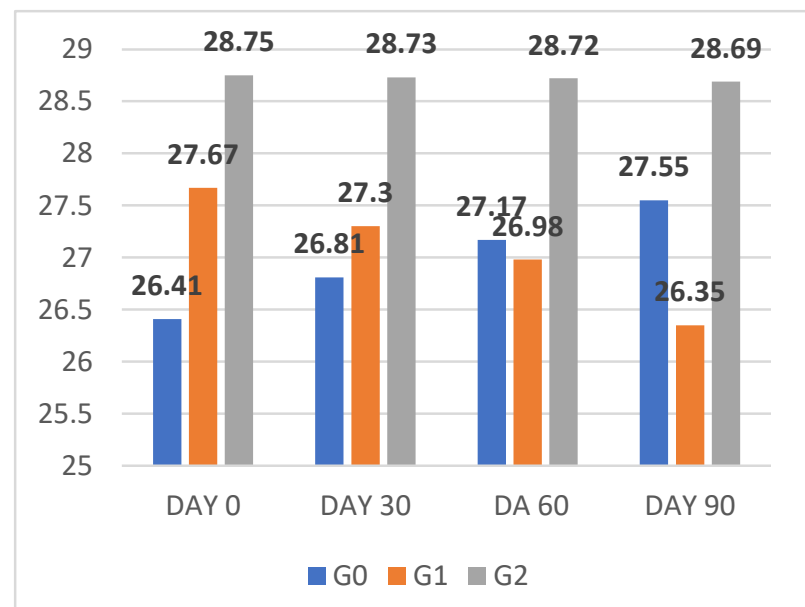

Figure 3. Comparison of means for BMI of females demonstrating the effect of barley water on BMI 
These results undoubtedly suggested that the barley water was able to significantly decrease the values of body mass index of the research participants. The study by Rajesh $e t$ al. [12] shows that barley flour is more effective than oat flour in improving BMI. The mean value of waist circumference of $\mathrm{G}_{1}$ at the day 0 , before the trial started was $36.46 \pm 3.1$ which dropped to $35.65 \pm 2.9$ at day 30 and further reduced to $34.2 \pm 2.7$ at day 60 and to a greater extent it dropped to
$32.95 \pm 2.7$ at day 90 . The mean value of waist circumference of $\mathrm{G}_{2}$ at the day 0 , before the trial started was $37.78 \pm 2.1$ which remained nearly same $37.77 \pm 2.6$ at day 30 and slightly reduced to $37.70 \pm 2.5$ at day 60 and evidently reduced to $37.15 \pm 2.4$ at day 90 . The results of $\mathrm{G}_{1}$ were highly significant as compared to $\mathrm{G}_{2}$. Whereas, the mean values of waist circumference of Go at day 0 was $34.86 \pm 2.5$ which increased significantly to $36.61 \pm 2.6$ at day 90 (Fig. 4).

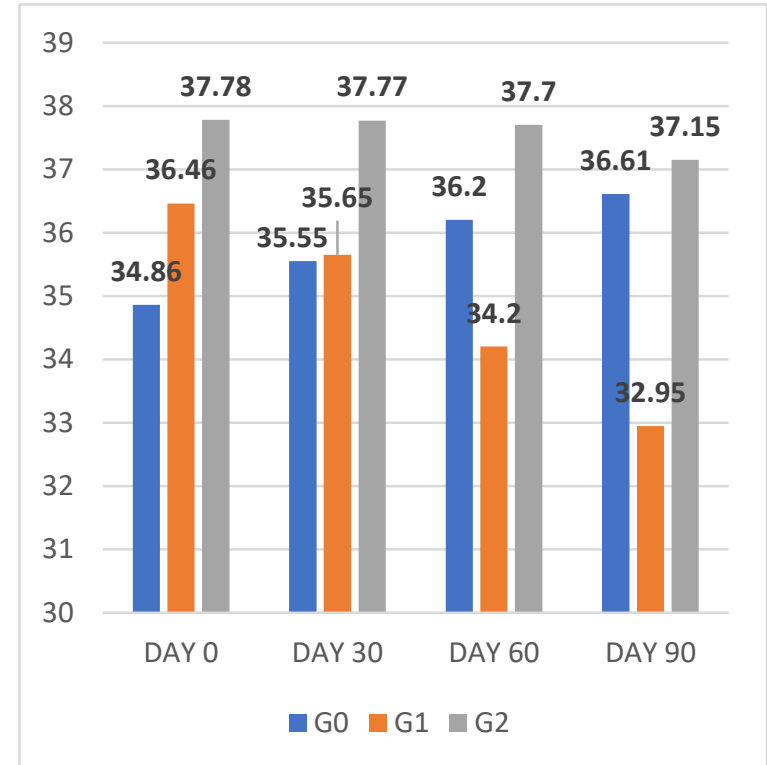

Figure 4. Comparison of means for Waist circumference of individuals representing the effect of barley water on WC

The reduction in weight ensured reduction in waist circumference. Barley water was effective in reducing weight loss thus giving evident results in anthropometric measurements. These results are inclined with the result of study by Mosikanon et al. [13] which shows that consuming beta glucan for 6 weeks by cardiovascular disease patients reduces waist circumference and blood pressure in them.

The mean value of waist-to-hip ratio of $\mathrm{G}_{1}$ at the day 0 , before the trial started was
$0.85 \pm 0.06$ which dropped to $0.83 \pm 0.06$ day 30 and further reduced to $0.81 \pm 0.05$ at day 60 and to a greater extent it dropped to $0.8 \pm 0.06$ at day 90. The mean value of waist-to-hip ratio of $\mathrm{G}_{2}$ at the day 0 , before the trial started was $0.87 \pm 0.44$ which remained same $0.87 \pm 0.05$ at day 30 and it reduced to $0.86 \pm 0.03$ at day 60 and remained similar $0.86 \pm 0.06$ at day 90 . Whereas, the mean values of waist-to-hip ratio of Go at day 0 was $0.85 \pm 0.37$ which increased significantly to $0.88 \pm 0.37$ at day 90 (Fig. 5). 


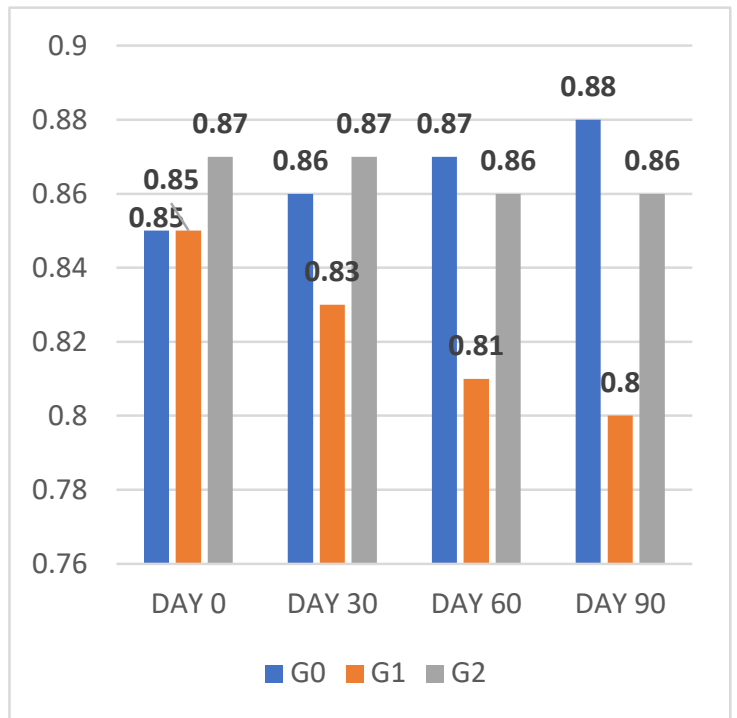

Figure 5. Comparison of means for $\mathrm{W} / \mathrm{H}$ ratio of females representing the effect of barley water on $\mathrm{W} / \mathrm{H}$ ratio

The reduction in weight ensured significant reduction in anthropometric measurements such as weight, waist circumference, hip circumference, waist-to-hip ratio. The study by Bhavani and Devi [14] is inclined with the result of the present study which shows that consuming complex carbs such as wheat, barley and oats improves waist and hip circumference and also waist to hip ratio due to the high fibre content of the cereals.

\section{Conclusion}

It can be concluded that Presence of abundant beta glucan (11.37\%) in barley which is a water-soluble fiber is competent in treating and/or preventing obesity. Barley water was a preferable option over barley powder which was convenient to consume drink. $10 \mathrm{~g}$ of Barley water was more productive in aiding weight loss among obese females when compared to dose of $5 \mathrm{~g}$ of barley water. It remarkably reduced body and waist circumference.

\section{Authors' contributions}

Conceived and designed the experiments: $\mathrm{N}$ Itrat \& A Nazir, Performed the experiments: M Ali, Analyzed the data: U Ahmad, Contributed materials/ analysis/ tools: Z Mushtaq, Wrote the paper: A Nazir \& N Itrat.

\section{Acknowledgement}

I would like to thank Allah Almighty for his blessings upon me. I am also grateful to my parents, friends and teachers for their support. A special thanks to my supervisor Ms. Nizwa Itrat for all her directions and recommendations throughout my study. Her attentiveness and keen interest played a major role in successfully completing the research. It was surely a great prerogative to work under her guidance. I would be pleased to thank Miss Maria Tahir who helped me with statistical analysis on my collected data. With her kind assistance I was able to compile and interpret the statistical results of my research study without any troublesome affairs.

\section{References}

1. Hales CM, Carroll MD, Fryar CD \& Ogden CL (2020). Prevalence of obesity and severe obesity among adults: United States, 2017-2018.

2. Vignaroli AG (2017). Barriers to Managing Childhood Overweight/ Obesity in American Indian Children.

3. Alberca RW, Oliveira LDM, Branco ACCC, Pereira NZ \& Sato MN (2020). Obesity as a risk factor for COVID-19: an 
overview. Cri Revs in Food Sci and Nutr $1-15$.

4. Sahoo K, Sahoo B, Choudhury AK, Sofi NY, Kumar R \& Bhadoria AS (2015). Childhood obesity: causes and consequences. J of Family Med and Pri Care 4(2): 187.

5. Idehen E, Tang $Y$ \& Sang S (2017). Bioactive phytochemicals in barley. $J$ of Food and Drug Anal 25(1): 148-161.

6. Zeng $\mathrm{Y}, \mathrm{Pu} \mathrm{X}, \mathrm{Du} \mathrm{J}$, Yang $\mathrm{X}, \mathrm{Li} \mathrm{X}$, Mandal M \& Yang J (2020). Molecular Mechanism of Functional Ingredients in Barley to Combat Human Chronic Diseases. Oxidative Medicine and Cellular Longevity, 2020.

7. Baik B (2016). Current and potential barley grain food products. Cereal Foods World 61(5): 188-196.

8. Taketa S, Yuo T, Tonooka T, Tsumuraya Y, Inagaki Y, Haruyama N \& Jobling SA (2012). Functional characterization of barley betaglucanless mutants demonstrates a unique role for CslF6 in $(1,3 ; 1,4)-\beta$-D-glucan biosynthesis. $J$ of Exp Bot 63(1): 381-392.

9. Kodama S, Shoda T, Machmudah S, Kanda H \& Goto M (2015). Enhancing pressurized water extraction of $\beta$-glucan from barley grain by adding $\mathrm{CO} 2$ under hydrothermal conditions. Chem Engin and Proc: Process Intensification 97: 4554.

10. Castillo C, García G, Hernández A \& Zamora M (2019). Proximate composition and energy value analysis of five varieties of malting barley. Inter $J$ of Food Sci and Biotechnol 4(2): 35.

11. Rahmani J, Miri A, Černevičiūtè R, Thompson J, de Souza NN, Sultana R \& Hekmatdoost A (2019). Effects of cereal beta-glucan consumption on body weight, body mass index, waist circumference and total energy intake: A meta-analysis of randomized controlled trials. Complementary Therapies in Med 43: 131-139.

12. Rajesh K, Satish G, Vivek J, Abhisheak S \& Mita K (2015). A comparative study of antiobesity property of barley and oat flour. Int J Ayur Pharma Res 3(1): 73-79.

13. Mosikanon K, Arthan D, Kettawan A, Tungtrongchitr R \& Prangthip P (2017). Yeast $\beta$-Glucan Modulates Inflammation and Waist Circumference in Overweight and Obese Subjects. J of Dietary Suppl 14(2): 173-185.

14. Bhavani V \& Devi NP (2020). "Visceral Fat for Miserable Life"!!-Determinants of Increased Waist Circumference among College Age Population. Inter J of Sci and Heal Res 5(1): 49-54. 